\title{
CONSUMERS' WILLINGNESS TO PAY FOR AGRICULTURAL LANDSCAPE IMPROVEMENTS IN LITHUANIA: ESTIMATION FRAMEWORK
}

\author{
Anastasija Novikova, Bernardas Vaznonis \\ Aleksandras Stulginskis University, Lithuania \\ anastasija.novikova@asu.lt; bernardas.vaznonis@asu.lt
}

\begin{abstract}
Agriculture not only supplies food and fibre to the society, but also provides other services, which are not revealed in the market prices. The role of agricultural activities is essential in forming and improving the landscape, in particular, for Lithuanian case study. Therefore, the paper focuses on development of the framework for estimation of consumers' willingness to pay for agricultural landscape improvements. The objectives of this paper are to present construction of the estimation framework for eliciting willingness to pay (WTP) for nonmarket agricultural landscape goods through choice experiments (CE) in Lithuania; then, to show the results of framework pre-test, and identify applicability of the framework designed. CE is a survey-based method implying creation of repetitive choice situations about alternatives of agri-environmental schemes for revealing how inhabitants of Lithuania value public goods from agricultural landscape (scenic views, variety of flora and fauna species, recreational infrastructure and services, the objects of cultural heritage), enabling to estimate Lithuanian residents' WTP and the demand for improvements of agricultural landscape. The results of the pilot survey have shown that the questionnaire was comprehensible and interesting to the respondents, revealing that the valuation of agricultural landscape is in demand by the society. The results of modelling, applying conditional logit, have shown a good model fit, allowing the usage of the estimation framework for the main survey and an estimation of consumers' willingness to pay for public goods/improvements from agricultural landscape.
\end{abstract}

Key words: agricultural landscape, choice experiments, willingness to pay, Lithuania, public goods.

\section{Introduction}

Agricultural activity is special, because during the production process not only private benefit is created (i.e. food and fibre), but it also gives benefits to society in the form of aesthetic value of the landscape, the space for recreation and other (Fleischer \& Tsur, 2009). Agriculture has essential impact on the landscape. Paracchini et al. (2016) describe the agricultural landscape as a cultural landscape composed of spatial units characterized by interrelation of different, yet identifiable, components such as natural conditions, farming systems, cultural heritage, and those who manage the land. In this context, Jones et al. (2016) affirm that in recognition of the cultural services that agricultural landscapes provide, these landscapes are now being defined both as physical structures managed for the purposes of agriculture and forestry and as cultural entities characterised by systems of land use and cultural practices. Landscape plays an important role in cultural, environmental and social spheres, and is a favorable resource to economy, because protection, management and planning of the cultural landscape may contribute to job creation in rural areas (Santos et al., 2016). Therefore, the positive role of agriculture, good farming practices have the potential to significantly increase the value of landscape, while the negative role may lead to impoverishment of landscape. Agri-environmental public goods and services as aesthetic value of agricultural landscape or preservation of biodiversity are created as by-products during production of market output. Farmers' reaction to agri-food price changes and changes in agricultural policy could influence the supply of these public goods and services (Santos et al., 2016).

The agrarian component has a considerable effect on the Lithuanian landscape. For hundreds of years, agriculture has been shaping the Lithuanian rural environment. At present, it also has an exclusive role in creation of agri-environmental public goods. According to data by the Lithuanian Land Fund (2016), 53.11\% of the surface land feature agricultural land, and arable land covers $49.67 \%$. The second pillar of the European Common Agricultural Policy is also focused on the agricultural landscape; moreover, the Landscape Stewardship Scheme was provided under the Lithuanian Rural Development programme during the 2007 - 2013 period. Nevertheless, Lithuanian residents' opinion is not taken into the account, even though they contribute to implementation of the agricultural policy. It is therefore important to assess Lithuanian rural residents' and visitors' attitudes towards landscape management, in particular, towards the role of agriculture in shaping the cultural landscape and its elements, and to assess the value of such public goods for society in view of the absence/lack of the market for them. This analysis could be useful for development of agri-environmental measures, their better adaptation to the expectations of society.

Choice experiments (CE) are widely applied to evaluation of environmental public goods as well as analysis of the attributes of agricultural landscape. Research has been conducted from the demand 
perspective, analysing consumers' willingness to pay for the agricultural landscapes' goods (for example, Takatsuka et al., 2006; Campbell, 2007; RodríguezOrtega, Bernués, \& Alfnes, 2016) as well as the supply perspective (for example, Christensen et al., 2011; Goibov et al., 2012; Villanueva et al., 2015). However, only few studies were done in Lithuania. Therefore, this paper focuses on evaluation of significance of the main attributes of agricultural landscape (scenic views, variety of flora and fauna species, recreational infrastructure and services, objects of cultural heritage) for Lithuanian residents, and, in particular, on development of the framework for estimation of consumers' willingness to pay for agricultural landscape improvements. The main aim of this paper is to present construction of the framework for estimation of consumers' willingness to pay for agricultural landscape through choice experiments in Lithuania; then, to show the results of framework pre-test and identify applicability of the framework designed. The pilot survey was conducted in February 2017. The paper is structured as follows: first, main aspects of the chosen CE method are presented; second, the survey and questionnaire design, focusing on the selection of attributes, construction and aims of the CE survey are shown; the results and discussion part presents the empirical research findings revealing suitability of the framework designed. Conclusions are drawn in the last section of the paper, highlighting main points for further research.

\section{Materials and Methods}

\section{Framework modelling}

$\mathrm{CE}$ is one of the stated preference techniques frequently used in agri-environmental valuation (Arriaza et al., 2008; Dominguez-Torreiro \& Soliño, 2011; Rodriguez-Entrena et al., 2012; Jianjun, 2013; Vivithkeyoonvong \& Jourdain, 2017). It allows consumers to express their preferences and choose between alternative hypothetical scenarios that differ in the magnitude of their effects (Lancaster, 1966; Bennett, 2001; Dominguez-Torreiro \& Soliño, 2011). Lancaster's Theory of Value (Lancaster, 1966) and Random Utility Theory (RUT) (Thurstone, 1927) are the main foundations of CE. Arriaza et al. (2008) affirms that the Theory of Value proposes that utilities for goods can be decomposed into individual utilities by their characteristics or attributes. Jianjun et al. (2013) adds that consumers' choices can be modelled as a function of attributes of the alternatives specific to a given choice problem. The RUT explains diversity of the opinions choosing the offered combinations (Thurstone, 1927). Econometric basis for current choice modelling theory stems from McFadden (1974) who later extended RUT to multiple comparisons and choices (McFadden and Train, 2000).
According to Lancaster (1966), consumers gain their utility not from the whole good, but rather from the attributes the good renders. According to the RUT, the subject chooses the alternative which gives the highest utility. Within this theoretical framework, subjects choose among alternatives according to the utility function with two components: systematic (i.e. observable) component plus random term (nonobservable by the researcher) (McFadden, 1974). Mathematically:

$$
U_{\text {in }}=V_{\text {in }}\left(Z_{i}, S_{n}\right)+\varepsilon_{\text {in }}
$$

where $U_{i n}$ is the utility provided by alternative $i$ to subject $n, V_{i n}$ is the systematic component of the utility, $Z_{i}$ is the vector of attributes of alternative $i$, $S_{n}$ is the vector of socio-economic characteristics of respondent $n$, and $\varepsilon$ is the random term.

Conditional logit (CL) model is one of the available probabilistic choice models, mostly used in CE (McFadden, 1974; Ben-Akiva \& Lerman 1985; Arriaza etal., 2008; Grammatikopolou etal.,2012). The condition of independent and identically distributed (IID) errors according to Gumbel distribution must be met using this model specification. This distribution in the error terms allows for verification of independence of irrelevant alternatives (IIA) property, known as Luce's axiom (Luce 1959). The axiom implies that the ratio of probabilities of choosing any pair of alternatives $\mathrm{i}$ and $\mathrm{j}\left(\mathrm{P}\left(/ \mathrm{C}_{n}\right) / \mathrm{P}\left(/ \mathrm{C}_{n}\right)\right)$ is not dependent on systematic utility of any other alternative within set of alternatives $\mathrm{C}_{n}$. According to $\mathrm{CL}$ model, the probability that an individual $n$ will choose alternative $i\left(\mathrm{P}_{i n}\right)$ among other alternatives $j(j=1 \ldots J)$ of set $\mathrm{C}_{n}$ is expressed by equation (McFadden, 1974):

$$
P_{i n}=\frac{\exp \left(\mu V_{i n}\right)}{\sum_{j \in C} \exp \left(\mu V_{j n}\right)}
$$

where $V_{\text {in }}$ is the systematic component of the utility provided by alternative $i$, and $\mu$ is a scale parameter which is inversely proportional to standard deviation of the error terms and usually is assumed to be equal to one (Ben-Akiva \& Lerman, 1985).

\section{Survey and questionnaire design}

Survey-based CE method, where hypothetical choice situations about alternatives of agrienvironmental programs pertaining to agricultural landscape are developed, have been employed in this paper. This allows revealing how residents in Lithuania value public goods from agricultural landscape to identify their attitudes concerning maintenance and improvements of these environmental public goods in the rural areas. One of the most important objectives for this research is selection of the attributes for the 
survey. As a result, the framework for estimation of consumers' willingness to pay for agricultural landscape improvements in Lithuania has covered the landscape elements, which might be largely affected by certain policy measures. Identification of these elements has been implemented according to the scientific literature analysis. This has enabled the authors of this paper to identify four attributes for implementation of the CE:

1. scenic views;

2. variety of flora and fauna species;

3. recreational infrastructure and services;

4. objects of cultural heritage.

The CE questionnaire has been designed to contain multiple choice questions (choice cards) about alternative policies for improvements of agricultural landscape in Lithuania. The $\mathrm{CE}$ questionnaire consists of three parts. The first part contains questions pertaining to respondents' opinions and their awareness of impacts caused by agriculture on the landscape. This part also presents the aim of the survey. The second part of the survey presents the role of agriculture in creation of public environmental goods on the agricultural landscape and contains choice situation questions. Consequently, this part of the questionnaire is focused on determining public view regarding the role of agriculture in terms of sustaining and improving scenic views of the agricultural landscape, preserving the flora and fauna, improving recreational infrastructure and services, and safeguarding the objects of cultural heritage. The following attributes of agricultural landscape have been presented to the respondents:

- Scenic views - extensive farming could enhance aesthetic value of the landscape. Environmentally-friendly farming practices (depending on the agricultural land use, crop structure, farming intensity, greening and other measures implementing the agri-environmental scheme) could create open and various mosaic landscape. Such landscape is very attractive to visitors of rural areas.

- Variety of flora and fauna species - extensive farming could have very positive role in preserving biodiversity and enhancing it. Different breeds of domestic animals and plant species could be valuable in the context of agricultural landscape, shaping active/ productive view of the landscape. Nonetheless, intensive farming leads to reduction of the areas of natural meadows, pastures and swamps, and, consequently, the landscape becomes monotonic. Rare and preserved plant species are disappearing due to the use of fertilisers. Mostly by food chain relations, this has a negative impact on other animals like birds and mammals.

- Recreational infrastructure and services recreational value could be understood as providing possibilities to use the goods from agricultural landscape. Roads, bicycle paths, resting fields and sleeping places, beaches, parks, avenues, information stands as well as rental of specific leisure services (bicycles, boats, ski) are needed for this purpose.

- Objects of cultural heritage. Maintenance of agricultural activities in rural areas determines the condition of heritage. Farmers are usually unique persons who are the conservators of valuable architecture, buildings, and objects of cultural heritage. It should be stressed that the remains of farm buildings, neglected objects of cultural heritage (manors, castles) spoil the landscape.

In the choice cards, the respondents were asked to select the combination they favour most out of two alternatives or the status quo provided. Status quo situation means current situation, i.e. non-application of any additional agri-environmental policies. Each option contains different combinations and levels of attributes as well as the cost of respective additional agri-environmental policy. The cost attribute is annual personal contribution for sustaining public goods from agricultural landscape. Each respondent was given four cards with choice situations, where he/she had to choose one alternative out of three. Three follow up questions are proposed after the choice situations. The first question is aimed at identifying whether or not the respondent has lexicographic preferences, for example, systemically ignoring certain attribute. The second question focuses on collection of information about general demand for suggested attributes, which are proposed as separate services of agricultural landscape. The last follow up question is aimed at identifying the motives of protesters not to pay for environmental public goods from agricultural landscape.

The third part contains questions about the respondent's economic and social status. This part of the questionnaire is set to collect the socioeconomic data about the respondents such as age, gender, education, occupation and income. Wang et al. (2007), Arriaza et al. (2008) have noted that the differences between respondents' socio-economic characteristics influence their willingness to pay for suggested attributes of agricultural landscape.

Upon the review of recent studies, the following socio-economic characteristics were selected: gender, age, area of residence, purposes of visits to rural areas, relation to agricultural activities, size of the household, and monthly net income per capita. The 
Example of a choice card in the questionnaire

\begin{tabular}{|l|c|c|c|}
\hline \multicolumn{1}{|c|}{ Attributes } & Program A & Program A & No program \\
\hline Scenic views, aesthetic value & greater variety & greater variety & No changes \\
\hline Variety of flora and fauna species & improvement 50\% & No changes & Improvement \\
\hline Recreational infrastructure and services & No changes & Recovery & EUR \\
\hline Objects of cultural heritage & 24 EUR & & 0 EUR \\
\hline $\begin{array}{l}\text { Personal contribution } \\
\text { (EUR per year for the next 5 years) }\end{array}$ & & \\
\hline Your choice & & $\square$ \\
\hline
\end{tabular}

interest and difficulty of the questionnaire have also been included in the last part of the questionnaire in order to understand the interest and importance of the current topic for the respondents, which is highly important for construction of the framework.

\section{Results and Discussion}

Pre-test of the estimation framework is the crucial point in application of choice experiments for estimation of willingness to pay for improvements in agricultural landscape. It has been stressed in recent studies (Hensher et al., 2005) that an untested questionnaire may cause considerable imperfections and errors during data modelling. Therefore, a choice experiment questionnaire has been tested using a pilot survey to check and, as may be required, improve the efficiency and appeal of the framework prior to conducting the main research.

The pilot survey was carried out in February, 2017. Four attributes of agricultural landscape, such as scenic views, variety of flora and fauna species, recreational infrastructure, services, and objects of cultural heritage, and the cost attribute were included during this pre-test. These covered 324 combinations $\left(3^{4} \times 4^{1}\right)$ in the full factorial design, resulting in excessive number of combinations to be presented to the respondents. Therefore, orthogonal experimental design of the survey has been developed using the SPSS program. As a result, 12 choice cards have been developed and divided randomly into three blocks, each consisting of four sets. These contain four attributes delivered at three levels and the cost attribute delivered at four levels. Table 1 illustrates an example of a choice card in the questionnaire.

57 questionnaires were distributed, 48 questionnaires were filled in, 3 questionnaires were eliminated due to incorrect completion, data of 45 questionnaires was analysed. The survey was implemented randomly by selecting respondents during seminars and other events. A total of 45 valid questionnaires has been obtained, delivering 540 choice observations. Two cases of non-willingness to pay for improvement in agricultural landscape have been identified on the basis of the status quo option chosen in all cards. Pre-test of the questionnaire has indicated that the questionnaire was comprehensible and interesting to the respondents. More than $70 \%$ of them stated that the topic is really interesting and $65 \%$ - that it was absolutely clear. The results of the pilot survey have implied that personal contribution to agricultural policy could be reduced.

Approximately $55 \%$ respondents of the pilot survey are women; mean age of the respondents is approximately 35 years old. More than $70 \%$ respondents live in urban areas. Majority of the households are comprised of 2 members. Average family size is 2.98 persons. Majority of the respondents were earning about 650 - 800 EUR monthly net income per person, and the minority - less than 200 EUR. More than $80 \%$ of the respondents think that agriculture has a positive impact on the landscape and about $14 \%$ - negative. Respondents' opinions concerning the impact of agri-environment elements on landscape are different. Mostly, the respondents have expressed support to the land use, crop structure and protection of water bodies, they think that these elements have the greatest effect on landscape aesthetics, scenic diversity and biodiversity.

In order to check applicability of the framework created for the analysis of consumer preferences towards agri-environmental public goods, two conditional logit (CL) models were run with STATA 13. The first model, named model I, was the basic specification that included only one independent variable - personal contribution or price. It is the base model or its basic specification. The decision to add only the price variable into the base model was based on the existing knowledge that consumers first always analysed the price before making any choice, with other determinants analysed further. The second model, named model II, showed the importance of the choice attributes in explaining consumer preferences towards different options of agri-environmental public goods (i.e. scenic views; variety of flora and 
Results obtained from CL model I and model II

\begin{tabular}{|l|c|c|c|c|c|c|}
\hline \multirow{2}{*}{ Variables } & \multicolumn{5}{c|}{ Model I } & \multicolumn{3}{c|}{ Model II } \\
\cline { 2 - 7 } & Coefficients & S.E. & p-Value & Coefficients & S.E. & p-Value \\
\hline PRICE & .0087718 & .0058183 & 0.132 & -.0153785 & .008404 & 0.067 \\
\hline VIEWS & & & & .0262318 & .0136219 & 0.054 \\
\hline WILD_L & & & .0417575 & .0135015 & 0.002 \\
\hline RECR & & & & .0573690 & .0133361 & 0.000 \\
\hline CULT & & & & .0298947 & .0150012 & 0.046 \\
\hline \multicolumn{7}{|c|}{ Model fit statistics } \\
\hline Log-likelihood & -278.07686 & & & -253.77891 & & \\
\hline$\chi^{2}$ & 2.26 & & & 50.85 & & \\
\hline (p-Value) & 0.1331 & & & 0.000 & & \\
\hline Pseudo-R ${ }^{2}$ & 0.0040 & & & 0.0911 & & \\
\hline Observations & 540 & & & 540 & & \\
\hline
\end{tabular}

fauna species; recreational infrastructure and services; objects of cultural heritage). In model II, utility was determined by the levels of five attributes (scenic views, variety of flora and fauna species, recreational infrastructure and services, objects of cultural heritage, personal contribution) in the choice sets (Table 2).

The results of model I show bad model fit: first, there is no negative sign by the price coefficient; second, its p-value is too high (0.132). This means that using the price variable to explain consumers' choices is not enough. Consequently, more variables need to be included into the model. Model II was run to identify whether or not new variables improve the model. In other words, to prove that model II is actually more appropriate that model I. Comparison of the Loglikelihood of model II with that of model I suggests that model II is more statistically significant, because its likelihood value is closer to zero (-253.779). The test to compare the LL function of an estimate, i.e. model II, against its related base model (model I) is referred to as the LL ratio-test. Comparing model II and model I, four additional variables are included (i.e. scenic views, aesthetic value, variety of flora and fauna species, recreational infrastructure and services, objects of cultural heritage). As a result, critical $\chi^{2}$ value is $9.5\left(\chi^{2}(4)\right.$ d.f. $\left.=9.4877\right)$ at $\alpha=0.05$. Here, $\chi^{2}$ value is 50.85 , which is higher than critical $\chi^{2}$ value. Therefore, model II is more statistically significant than the base model (model I). Despite the small number of observations, the results of model II show that almost all variables are statistically significant at 0.05 level. The price coefficient is significant at 0.07 level. It should be noted that all coefficients of the attributes are positive and the price coefficient is negative, suggesting that people are likely to accept an agri-environmental policy with lower personal monetary contribution. Also, it shows a good fit of model II.

In addition, it should be noted that the variables used in model II are correct and statistically significant, and the conditional logit model could be used for modelling of data generated by main surveys and estimation of respondents' willingness to pay for public goods from agricultural landscape. At this stage, inclusion of respondents' socio-economics characteristics into the modelling process and estimation of willingness to pay for public goods from agricultural landscape would be unreasonable due to scarce data. It will be estimated after the main survey.

\section{Conclusions}

Agriculture not only supplies society with food and fibre, but also provides other services, which are not revealed in the market prices. Positive role of agriculture, good farming practices can significantly increase the value of landscape, while their negative role might lead to landscape impoverishment. Agrienvironmental public goods and services as aesthetic value of agricultural landscape or preservation of biodiversity are created as by-products during production of market output. Agricultural policy makes essential contribution into provision of such goods and services. As they are not measured in the market, special valuation techniques, such as $\mathrm{CE}$, should be applied to assess the value of agrienvironmental public goods.

The main finding of this paper is creation and testing of the framework for estimation of consumers' willingness to pay for agricultural landscape improvements in Lithuania for further application and main survey. The results of the pilot survey have demonstrated the relevance and significance of the 
topic selected, which is substantiated by respondents' answers that it was interesting and comprehensible. They have also shown that all attributes have been selected properly and should be included into the framework. However, the pre-test has also shown that some improvements could be made, such as minor reduction in the value of personal contribution and inclusion of an additional price combination.
Modelling results have shown a good model fit, including all attributes (scenic views, variety of flora and fauna species, recreational infrastructure and services, objects of cultural heritage, personal contribution) and its suitability for the main survey. The tested CL could be selected as an appropriate model for further research.

\section{References}

1. Arriaza, M., Gomez-Limon, J.A., Kallas, Z., \& Nekhay, O. (2008). Demand for non-commodity outputs from mountain olive groves. Agricultural Economics Review, 9(1), 5 - 23.

2. Ben-Akiva, M., \& Lerman, S. (1985). Discrete choice analysis: theory and application to travel demand. MIT press. Cambridge, MA.

3. Bennett, J.B.R. (2001). The choice modelling approach to environmental valuation, new horizons in environmental economics. Cheltenham: Edward Elgar.

4. Campbell, D. (2007). Willingness to Pay for Rural Landscape Improvements: Combining Mixed Logit and Random-Effects Models. Journal of Agricultural Economics. 58(3), 467 - 483. DOI: 10.1111/j.14779552.2007.00117.x.

5. Christensen, T., Branth, P.A., Helle, O.N., Morten, R.M., Berit, H., \& Sigrid, D. (2011). Determinants of farmers' willingness to participate in subsidy schemes for pesticide-free buffer zones-A choice experiment study. Ecological Economics, 70 (8), 1558 - 1564. DOI: 10.1016/j.ecolecon.2011.03.021.

6. Domínguez-Torreiro, M., \& Soliño, M. (2011). Provided and perceived status quo in choice experiments: Implications for valuing the outputs of multifunctional rural areas. Ecological Economics, 70(12), 2523 253. DOI: 10.1016/j.ecolecon.2011.08.021.

7. Fleischer, A., \& Tsur, Y. (2009). The Amenity Value of Agricultural Landscape and Rural-Urban Land Allocation. Journal of Agricultural Economics. 60 (1), 132 - 153. DOI: 10.1111/j.1477-9552.2008.00179.x.

8. Goibov, M., Schmitz, P.M., Bauer, S., \& Ahmed, M.N. (2012). Application of a choice experiment to estimate farmers preferences for different land use options in Northern Tajikistan. Journal of Sustainable Development, 5(5), 2 - 16.

9. Grammatikopouloua, I., Poutaa, E., Salmiovirtab, M., \& Soini, K. (2012). Heterogeneous preferences for agricultural landscape improvements in southern Finland. Landscape and Urban Planning, 107, 181 191. DOI: 10.1016/j.landurbplan.2012.06.001.

10. Hensher, D.A., Rose, J.M., \& Greene, W.H. (2005). Applied choice analysis: A primer. United Kingdom, Cambridge University Press.

11. Jianjun, J., Chong, J., Thuy, T.D., \& Lun, L. (2013). Public preferences for cultivated land protection in Wenling City, China: A choice experiment study. Land Use Policy, 30, 337 - 343. DOI: 10.1016/j. landusepol.2012.04.003.

12. Lancaster, K.J. (1966). A new approach to consumer theory. Journal of Political Economy. 74, 132 - 157.

13. McFadden, D. (1974). Conditional logit analysis of qualitative choice behaviour. In: Zarembka, P. (Ed.), Frontiers in Econometrics. New York: Academic Press, pp. 105 - 142.

14. McFadden, D., \& Train, K. (2000). Mixed MNL Models for Discrete Response. Journal of Applied Econometrics, 15(5), $447-470$.

15. Ministry of Agriculture of the Republic of Lithuania. 2014. Lithuania - Rural Development Programme 2014 - 2020. Lithuania.

16. Nacionalinė Žemès Tarnyba Prie Žemès Ūkio Ministerijos. (2015). Lietuvos Respublikos Žemès Fondas. 2015 m. Sausio 1 d. Vilnius (Lithuanian Land Fund, 2016). (in Lithuanian).

17. Paracchini, M.L., Correia, T.P., Loupa-Ramos, I., Capitani, C., \& Madeira, L. (2016). Progress in indicators to assess agricultural landscape valuation: How and what is measured at different levels of governance. Land use Policy. 53, 71 - 85. DOI: 10.1016/j.landusepol.2015.05.025.

18. Rodríguez-Entrena, M., Barreiro-Hurlé, J., Gómez-Limón, J.A., Espinosa-Goded, M., \& CastroRodríguez, J. (2012). Evaluating the demand for carbon sequestration in olive grove soils as a strategy toward mitigating climate change. Journal of Environmental Management. 112, 368 - 376. DOI: 10.1016/j. jenvman.2012.08.004. 
19. Rodríguez-Ortega, T., Bernués, A., \& Alfnes, F. (2016). Psychographic profile affects willingness to pay for ecosystem services provided by Mediterranean high nature value farmland. Ecological Economics, 128, 232 - 245. DOI: 10.1016/j.ecolecon.2016.05.002.

20. Santos, J.L., Madureira, L., Ferreira, A.C., Espinosa, M., \& Gomez, P.S. (2016). Building an empiricallybased framework to value multiple public goods of agriculture at broad supranational scales. Land Use Policy. 53, 56 - 70. DOI: 10.1016/j.landusepol.2015.12.001.

21. Takatsuka, Y., Cullen, R., Wilson, M., \& Wratten, S. (2006). Values of Ecosystem Services on Arable Land and the Role of Organic Farming. In: the 3rd World Congress of Environmental and Resource Economists. Kyoto, Japan on July $3-7,2006$.

22. Thurstone, L. (1927). A law of comparative judgement. Psychological Review. 34 (4), 273 - 286.

23. Villanueva, A.J., Gómez-Limón, J.A., Arriaza, M., \& Rodríguez-Entrena, M. (2015). The design of agri environmental schemes: Farmers' preferences in southern Spain. Land use Policy, 46, 142 - 154. DOI: 10.1016/j.landusepol.2015.02.009.

24. Vivithkeyoonvong, S., \& Jourdain, D. (2017). Willingness to pay for ecosystem services provided by irrigated agriculture in Northeast Thailand. International Journal of Biodiversity Science, Ecosystem Services \& Management, 13(1), 14 - 26. DOI: 10.1080/21513732.2016.1242093.

25. Wang, X., Bennett, J., Xie, C., Zhang, Z., \& Liang, D. (2007). Estimating non-market environmental benefits of the conversion of cropland to forest and grassland program: A choice modelling approach. Ecological Economics, 63(1), 114 - 125. DOI: 10.1016/j.ecolecon.2006.10.001. 